\title{
Comparative Growth Performance of Mixed-Sex and Monosex Nile Tilapia Population in Freshwater Cage Culture System under Indian Perspective
}

\author{
Suman Bhusan Chakraborty (Corresponding author) \\ Dept. of Zoology, Serampore College \\ Serampore, Hooghly 712201, West Bengal, India \\ Tel: 91-033-2662-2322_E-mail: sumanbc76@gmail.com \\ Samir Banerjee \\ Aquaculture Research Unit, Department of Zoology, University of Calcutta \\ 35 Ballygunge Circular Road, Kolkata 700019, West Bengal, India \\ Tel: 91-033-2461-4959Ｅ-mail: samirbancu@gmail.com
}

The research is financed by the University Grants Commission (Minor Research Project, No.F. PSW - 032/07-08; S.No. - 85996) (Sponsoring information).

\begin{abstract}
Cage culture is one of the important methods for intensive culture of tilapia in large water impoundments. But, information related to growth performance of androgen-treated monosex tilapia population during cage culture under the ecological conditions of India is limited. The aim of this study was to compare the growth potential of control, mixed-sex and androgen-treated, monosex tilapia in confined environment of cages. Control and hormone treated fish were stocked separately in mesh cages at a density of $50 \mathrm{fry} / \mathrm{m}^{3}$ and it was found that the androgen treated monosex fish grew significantly larger than their control mixed-sex counterparts. The monosex population showed a significantly higher weight, length, depth, specific growth rate, daily weight gain, protein efficiency ratio and body protein content than the mixed-sex tilapia population. Thus, culture of hormone treated monosex tilapia in cages can be considered ideal for augmented production of the fish under Indian context.
\end{abstract}

Keywords: Cage culture, Nile Tilapia, Androgen treatment, Mixed-sex, Monosex, Growth potential

\section{Introduction}

The Nile tilapia, Oreochromis niloticus (Linnaeus, 1758) is a widely cultured species because it grows and reproduces in a wide range of environmental conditions and tolerates stress induced by handling (Tsadik and Bart 2007). The fish is currently ranked second only to carps in global production (Ridha 2006). Previously, tilapia was consumed mainly in Africa and Asia but nowadays it has been touted as the "new white fish" replacing the depleted ocean stocks of cod and heck, leading to a worldwide demand for the fish (Yue and Zhou 2008). The efficiency of reproduction in tilapia has paradoxical consequences. This aptitude allows easy and rapid propagation of the fish in various environmental conditions, but can as well be a source of problem. Within a limited environment, uncontrolled multiplication of the fish not only reduces the faunal diversity of the system but also produces dwarf fish population of poor market value (Coleman 2001; Hepher and Pruginin 1981). Monosex culture of male tilapia is postulated to solve this problem and dietary supplementation of synthetic androgens is a potent method for production of all-male tilapia population (Guerrero 1982; Macintosh et al 1985; Gale et al 1999; Beardmore et al 2001; Smith and Phelps 2001). In a previous study, monosex population of male tilapia was produced by treating fry with a synthetic male hormone $17 \alpha$-methyltestosterone (17 $\alpha \mathrm{MT})$ at a treatment regime of $10 \mathrm{mg} / \mathrm{kg}$ food for 30 days (Chakraborty et al 2007). The predominant advantage of monosex culture can be achieved in such aquaculture situations where one sex displays marked growth superiority, as in tilapia (Beardmore et al 2001). Thus, culture of such hormone treated monosex tilapia in confined system might prove effective to induce a positive approach towards tilapia culture in India. 
Tilapia has been widely introduced in the shallow and seasonal ponds of eastern region of India (Sugunan 1995). It is rapidly gaining popularity among the fish farmers as a readily available source of animal protein in the diets of rural and urban dwellers belonging to the lower socioeconomic strata. However, such indiscriminate introduction of the exotic fish into the open waters has generated a lot of debate in recent years. The ecologists and aquaculturists are concerned with the adverse effect of this exotic group on the indigenous fish population (Bartley and Martin 2004; De Silva et al 2004). Cage culture can provide an effective measure to this problem. Tilapia can be cultured at high densities in mesh cages that maintain free circulation of water. It ensures flexibility in management practices with easy and low cost of harvesting. Such culture method is found suitable for tilapia as it provides means for not only more intensive production, but also controlling wild spawning and overpopulation. It can be applied in existing bodies of water that cannot be drained or seined and would otherwise not be suitable for aquaculture. But, this culture method is yet to be commercialized on a wide scale basis and is still in its pilot stage in India. Moreover, only a few published data on the growout performance of androgen treated Oreochromis niloticus in the Indian context is available (Pandian and Varadaraj 1988). Hence, the propagation potentiality of sex-reversed tilapia population under cage culture system must be clearly documented. Considering these aspects, the present study aims to evaluate the comparative growth performance of the control mixed-sex and androgen treated monosex tilapia in cage culture system under the climatic and ecological conditions prevailing in the Gangetic plains of West Bengal, India.

\section{Methods}

Three days old mixed sex juveniles of Nile tilapia (mean weight $0.025 \pm 0.009 \mathrm{~g}$; mean length $1.25 \pm 0.012 \mathrm{~cm}$ ) were collected from the Fish Hatchery at Naihati, West Bengal. The fish were initially reared in glass aquaria at laboratory for one month and thereafter they were transferred to mesh cages for further five months of culture. In the laboratory, the fish were divided into two equal groups $(\mathrm{n}=50)$. During the first 30 days, one of the groups was given control diet at a rate of $20 \%$ body weight/day while the other was fed with $17 \alpha$ methyltestosterone (17 $\alpha \mathrm{MT})$ treated diet with a dose of $10 \mathrm{mg} / \mathrm{kg}$ at the same rate. This optimal hormone treatment regime for production of almost $100 \%$ male tilapia population was deduced through our previous study (Chakraborty et al 2007) and hormone treated diets were prepared by the alcohol evaporation technique (Shelton et al 1978). In brief, during the previous study, the fish were fed with differential hormone doses $(5 \mathrm{mg} / \mathrm{kg}, 10 \mathrm{mg} / \mathrm{kg}, 20 \mathrm{mg} / \mathrm{kg}$ and $30 \mathrm{mg} / \mathrm{kg}$ food) for differential time period (15 days, 30 days, 45 days and 60 days) (Chakraborty et al 2007). The differential amount of $17 \alpha \mathrm{MT}$ was dissolved in $95 \%$ ethanol and then mixed with the pellets ( 1 litre ethanol $/ \mathrm{kg}$ pellets). The $17 \alpha \mathrm{MT}$ containing wet pellets were dried overnight in the open air. Control pellets were prepared similarly without the addition of $17 \alpha \mathrm{MT}$. All the hormone treatment regimes yielded significantly higher $(\mathrm{P}$-value $<0.05)$ percentage of males compared to the control. Interestingly, the treatment regime of $10 \mathrm{mg} / \mathrm{kg}$ for 30 days yielded almost $100 \%$ male population that was significantly higher $(\mathrm{P}$-value $<0.05)$ than other lower dose or duration treatment categories but with no significant difference (P-value $>0.05$ ) from other higher dose or duration treatment categories (Chakraborty et al 2007). Thus, the treatment regime of $10 \mathrm{mg} / \mathrm{kg}$ for 30 days was taken as the optimum treatment regime for the present study.

After one month, the control and androgen treated tilapia were transferred to two separate $1 \mathrm{~m}^{3}$ standing surface cages made of bamboo frames and nylon wires with a mesh size of $1.3 \mathrm{~cm}$ at a stocking density of $50 \mathrm{fry} / \mathrm{m}^{3}$. The cages were equipped with covers to prevent fish losses from jumping or bird predation, placed in a large natural pond selecting an ideal location to allow sufficient water current and easy access for management practices and were separated from each other as well as the bottom substrate by enough distance to optimize water quality. During this period, both the fish groups were given control food (crude protein content 30\% and total digestible energy $3000 \pm 400$ $\mathrm{kcal} / \mathrm{Kg}$ food) made from a mixture of fine fish meal and rice bran, sieved to a size of less than $1 \mathrm{~mm}$, at a rate of $10 \%$ body weight per day for the first two months and 5\% per day for the rest three months. The total daily feed ration was divided into four equal portions. The experiment was conducted in three replicating units for statistical validation. Throughout the entire culture period different water quality parameters like temperature, $\mathrm{DO}_{2}$, free $\mathrm{CO}_{2}, \mathrm{pH}$, total alkalinity and turbidity were regularly monitored using the standard procedures of American Public Health Association (APHA 1998) and maintained within ideal value limits for tilapia growth (data not shown).

Fish from each cage were measured individually for weight, length and depth every 4 weeks and at the end of the trial. Besides, growth parameters like specific growth rate (SGR), daily weight gain (DWG), food conversion ratio (FCR), protein efficiency ratio (PER) and apparent net protein utilization (ANPU) were measured according to standard formulation (Pechsiri and Yakupitiyage 2005) at the end of the culture period. Equal amount of wet muscle tissue from 10 fish from each experimental set were taken to determine proximate body composition using standard methods (AOAC 1984). Moisture content was measured by drying a sample at $105^{\circ} \mathrm{C}$ in an oven for 24 hours and ash content was estimated by burning the sample at $550^{\circ} \mathrm{C}$ overnight in a muffle furnace. Crude protein and crude lipid were determined using the Kjeltec system 1026 distilling unit and Soxtec system HT 1043 (Tecator, Hognas, Sweden) respectively. To determine these body composites by wet mass, the proportion of dry tissue composed of protein, fat and ash was multiplied by percent solids from the original sample. The percent solid was calculated as the ratio of dry mass to wet mass. The results were reported as the mean \pm standard error (SE). When appropriate, Duncan's multiple 
test (at 5\%) (Duncan 1955) was applied to evaluate the differences among means. The statistically homogenous means were denoted by similar alphabets.

\section{Results}

The androgen treatment regime applied in the study could yield almost $100 \%$ male tilapia population (Chakraborty et al 2007). The survival percentage of the fish for both the mixed-sex and monosex culture was around $90 \%$. The growth patterns (Figure 1) in the mixed-sex and monosex groups depicted that after the first month of culture the MT treated monosex group grew more ( $\sim 2$ fold) than the control mixed-sex. The final growth at the end of 6-month culture duration of the monosex population was $\sim 3$ fold higher than that of the mixed-sex (P-value $<0.01$ ) (Figure 1A). Among the mixed-sex population, the control males grew significantly more than the females $(\mathrm{P}$-value $<0.05)($ Table 1$)$. Moreover, the control females showed a significantly lower value of length compared to the males $(\mathrm{P}$-value $<0.05)$ but, for depth, there was no significant difference between the sexes in the growth pattern (Table 1). The monosex tilapia grew significantly more than the mixed-sex fish in these two growth aspects also (Figures 1B, 1C). DWG of the mixed-sex tilapia population was significantly less than that of the monosex group (Table 2). SGR of the monosex fish was significantly high than its mixed-sex counterpart (Table 2). But, FCR for the mixed-sex group was significantly more compared to the monosex group (Table 2). The mixed-sex control group had significantly less PER value compared to the hormone treated monosex category (Table 2). Control males had the highest water content and the lowest protein content of all the groups while the treated males possessed the highest amount of protein and the lowest water content (Table 3). Control females had the highest fat content while control males had the lowest (Table 3). In addition, ash content was found highest in hormone treated group and lowest in control male category (Table 3). ANPU decreased significantly for the monosex category compared to the mixed-sex group (Table 2).

\section{Discussion}

Increase in freshwater fish production can result from the development and adoption of new technologies and improvement in the economic efficiency of farming operations. Tilapia has good potential for the enhancement of production in the fishery sector of India but considerable research is required to adopt different techniques of tilapia culture that are practiced in other countries.

The high survival percentage of fish for both the mixed-sex and monosex categories may be attributed to the protected environment of cages (Dan and Little 2000) and indicates that hormone treatment has no adverse effect on general fish health. The mesh size and arrangement of cages provide adequate open space for good water circulation through the cage to renew the oxygen supply and remove waste. The growth pattern of mixed-sex and monosex Nile tilapia population in the present study compared well with other studies. The higher growth rates of control males compared to control females (Table 1) might be due to increased energy being channeled towards metabolic maintenance and somatic growth in males while the females use considerable energy for spawning (Tran-Duy et al 2008). The growth curves of mixed-sex and monosex fish in cages were more or less linear (Figure 1A) indicating that the critical standing crop in cages was not exceeded (Diana et al 1994) possibly due to the addition of supplemented food. A few studies have demonstrated the enhanced yield of monosex male Nile tilapia populations under experimental conditions (Mair et al 1995). In Oreochromis mossambicus (Peters, 1852) also, 17 $\alpha$ MT treated fish is reported to show higher growth compared to the untreated fish reared under similar conditions (Macintosh et al 1985). Dan and Little (2000) observed that on average, monosex tilapia grew more than $10 \%$ faster than mixed-sex fish in cages. Several studies are in agreement that testosterone produces muscle hypertrophy by increasing muscle protein synthesis (Bhasin et al 2001). The increased growth performance and greater protein content of the androgen treated fish can surely be analyzed considering this knowledge. In many fish including tilapia, it has been reported that the protein requirement of the fish decreased with increasing size (El-Saidy and Gaber 2005). Our study has also indicated the same as observed from the decreased ANPU value with increased size in monosex population than that in the smaller mixed-sex fish. There was a general decrease in FCR and increase in PER for monosex fish than the mixed-sex ones. Such observation may be related to the fact that FCR decreases while PER increases with increased feeding rate (Pechsiri and Yakupitiyage 2005). Moreover, hormone treatment can increase the SGR and DWG of the fish. Similar values of individual growth for monosex tilapia, as in our study, were also observed by Diana et al $(1991,1994)$. It has been observed that for a given food composition, the body protein percentage on a wet weight basis is mainly affected by the body weight in salmonids (Shearer 1994). Similar observations have been noticed in Nile tilapia also where body protein content increases with wet weight (Pouomogne and Mbongblang 1993; Abdelghany and Mohammed 2002). This explains the higher protein content of the treated males than corresponding controls. Changes in body composition, particularly in body fat content, might influence feed intake in fish (Tran-Duy et al 2008). In the present study, the highest body fat content but lowest weight of control females might indicate a negative correlation between the two factors. However, the hypothesis was not explicitly expressed considering the comparative weight and body fat content of control and hormone treated males. 
In view of the relatively wide regional distribution of tilapia in India and its acceptability by the consumers, high priority is placed on the modification and improvements of the techniques for its culture. Culture of tilapia as a cash crop has two basic options: mixed-sex culture and the culture of monosex male populations. Regular culture without sex separation has often failed in the past because of the "wild spawning" of the tilapia that produces a large number of fry which stunt the entire population. Culture of monosex male tilapia resolves this problem. The management flexibility of intensive close culture systems can be achieved in open water through cage culture method. In spite of a relatively short history, cage culture of tilapia has spread rapidly throughout the world (Coche 1982). It requires a low capital investment compared to other intensive culture methods but allows for the benefits of such close culture systems. Another important benefit of cage culture is the ease and low cost of harvesting. Besides, fish in cages can obtain a small amount of natural food resources along with the necessary supplementary diets. Thus, the major conclusions that can be articulated from the present study are: 1 . The hormone treated males show higher growth rates than their control counterparts, 2. Additional advantages of larger fish and higher yields are gained through culture of such sex reversed fish, 3. Intensive culture of tilapia in the confined environment of cages can reduce the adverse ecological impact, if any, of tilapia culture in open water impoundments and 4. Cage culture of androgen treated monosex tilapia population can be postulated as the ideal method of choice for an eco-socio-economically sustainable tilapia culture in India.

\section{Acknowledgement}

The research is financed by the University Grants Commission (Minor Research Project, No.F. PSW - 032/07-08; S.No. - 85996). The Principal, Serampore College is also acknowledged for giving permission for conducting the research work.

\section{References}

Abdelghany, A. E. \& Mohammed, H. A. (2002). Effects of feeding rates on growth and production of Nile tilapia, common carp and silver carp polycultured in fertilized ponds. Aquaculture Research, 33, 415-423.

AOAC. (1984). Official methods of the Association of Official Analytical Chemists. $14^{\text {th }}$ edn. Association of Official Analytical Chemists, Arlington, VA, USA pp. 1298.

APHA. (1998). Standard Methods for the Examination of Water and Wastewater. $20^{\text {th }}$ edn. APHA (American Public Health Association), Washington, USA.

Bartley, D.M. \& Martin, F. (2004). Introduction of alien species/strains and their impact on biodiversity. In: M.V. Gupta, D.M. Bartley \& B.O. Acosta (Eds.) Use of genetically improved and alien species for aquaculture and conservation of aquatic biodiversity in Africa. Worldfish Center Conference Proceedings No. 68. The Worldfish Center, Penang, Malaysia, Pp. 16-21.

Beardmore, J.A., Mair, G.C. \& Lewis, R.I. (2001). Monosex male production in finfish as exemplified by tilapia: applications, problems, and prospects. Aquaculture, 197, 283-301.

Bhasin, S., Woodhouse, L., \& Storer, T. W. (2001). Proof of the effect of testosterone on skeletal muscle. Journal of Endocrinology, 170, 27-38.

Chakraborty, S. B., Sarbajna, A., Mazumdar, D., \& Banerjee, S. (2007). Effects of differential dose and duration of 17-methyltestosterone treatment on sex reversal of Nile tilapia, Oreochromis niloticus at different age groups under Indian perspective. Asian Journal of Microbiology, Biotechnology \& Environmental Science, 9 (3), 705-710.

Coche, A. G. (1982). Cage culture of tilapia. In: R.S.V. Pullin \& R.H. Lowe-McConnell (Eds.). The Biology and Culture of Tilapias. ICLARM conference Proceedings 7. International Center for Living Aquatic Resources Management, Manila, Philippines, pp. 432.

Coleman, R. (2001). Cichlids and Science: Bad Cichlids? Cichlid News Magazine, 10(2), 32-34.

Dan, N.C. \& Little, D.C. (2000). The culture performance of monosex and mixed-sex new-season and overwintered fry in three strains of Nile tilapia (Oreochromis niloticus) in northern Vietnam. Aquaculture, 184, 221-231.

De Silva, S.S., Subasinghe, R.P.D., Bartley, M. \& Lowther, A. (2004). Tilapias as alien aquatics in Asia and the Pacific: a review. FAO Fisheries Technical Paper. No. 453. Rome, FAO. 65p.

Diana, J.S., Lin, C.K. \& Jaiyen, K. (1994). Supplemental feeding of tilapia in fertilized ponds. Journal of World Aquaculture Society, 25(4), 497-506.

Diana, J.S., Lin, C.K. \& Schneeberger, P.J. (1991). Relationships among nutrient inputs, water nutrient concentrations, primary production, and yield of Oreochromis niloticus in ponds. Aquaculture, 92, 323-341.

Duncan, D. B. (1955). Multiple range and multiple F tests. Biometrics, 11, 1-42. 
El-Saidy, D. M. S. D. \& Gaber, M. M. A. (2005). Effect of dietary protein levels and feeding rates on growth performance, production traits and body composition of Nile tilapia, Oreochromis niloticus (L.) cultured in concrete tanks. Aquaculture Research, 36, 163-171.

Gale, W.L., Fitzpatrick, M.S., Lucero, M., Contreras-Sanchez, W.M. \& Schreck, C.B. (1999). Masculinization of Nile tilapia (Oreochromis niloticus) by immersion in androgens. Aquaculture, 58, 215-226.

Guerrero, R.D.III. (1982). Control of tilapia reproduction. In: R.S.V. Pullin \& R.H. Lowe-McConnel (Eds.). The biology and culture of tilapias, ICLARM Conference Proceedings 7. International Center for Living Aquatic Resource Management, Manila, Philippines, Pp. 309-316.

Hepher. \& Pruginin. (1981). Commercial Fish Farming. John Wiley and Sons, New York. pp. 291.

Macinosh, D.J., Varghese, T.J. \& Satyanarayana, G.P. (1985). Hormonal sex reversal of wild-spawned tilapia in India. Journal of Fish Biology, 26(2), 87-94.

Mair, G.C., Abucay, J.S., Beardmore, J.A. \& Skibinski, D.O.F. (1995). Growth performance trials of genetically male tilapia (GMT) derived from YY-males in Oreochromis niloticus L.: On station comparisons with mixed sex and sex reversed male populations. Aquaculture, 137, 313-322.

Pandian, T. J. \& Varadaraj, K. (1988). Techniques for producing all-male and all-triploid Oreochromis mossambicus. In: R. S. V Pullin, T. Bhukaswan, K. Tonguthai, \& J. L. Maclean (Eds.). The Second International Symposium on Tilapia in Aquaculture. ICLARM Conference Proceedings 15. Department of Fisheries, Bangkock, Thailand, and International Center for Living Aquatic Resources Management, Manila, Philippines, 243-249.

Pechsiri, J. \& Yakupitiyage, A. (2005). A comparative study of growth and feed utilization efficiency of sex-reversed diploid and triploid Nile tilapia, Oreochromis niloticus L. Aquaculture Research, 36, 45-51.

Pouomogne, V. \& Mbongblang, J. (1993). Effect of feeding rate on the growth of tilapia (Oreochromis niloticus) in earthen ponds. The Israeli Journal of Aquaculture - Bamideh, 45, 147-153.

Ridha, M. T. (2006). Comparative study of growth performance of three strains of Nile tilapia, Oreochromis niloticus, L. at two stocking densities. Aquaculture Research, 37, 172-179.

Shearer, K. D. (1994). Factors affecting the proximate composition of cultured fishes with emphasis on salmonids. Aquaculture, 119, 63-88.

Shelton, W. L., Hopkins, K. D., \& Jensen, G. L. (1978). Use of hormones to produce monosex tilapia for aquaculture. In: R. S. V Pullin, T. Bhukaswan, K. Tonguthai, \& J. L. Maclean (Eds.). The Second International Symposium on Tilapia in Aquaculture. ICLARM Conference Proceedings 15. Department of Fisheries, Bangkock, Thailand, and International Center for Living Aquatic Resources Management, Manila, Philippines, 10-33.

Smith, E. S. \& Phelps, R. P. (2001). Impact of feed storage conditions on growth and efficacy of sex reversal of Nile tilapia. North American Journal of Aquaculture, 63(3), 242-245.

Sugunan, V.V. (1995). Reservoir fisheries of India. FAO Fisheries Technical Paper, No. 345. Rome, FAO. 423p.

Tran-Duy, A., Schrama, J. W., van Dam, A. A. \& Verreth, J. A. J. (2008). Effects of oxygen concentration and body weight on maximum feed intake, growth and hematological parameters of Nile tilapia, Oreochromis niloticus. Aquaculture, 275, 152-162.

Tsadik, G. G. \& Bart, A. N. (2007). Effects of feeding, stocking density and water-flow rate on fecundity, spawning frequency and egg quality of Nile tilapia, Oreochromis niloticus (L.). Aquaculture, 272, 380-388.

Yue, Y-R. \& Zhou, Q-C. (2008). Effect of replacing soybean meal with cottonseed meal on growth, feed utilization and hematological indexes for juvenile hybrid tilapia, Oreochromis niloticus x O. aureus. Aquaculture, 284, $185-189$. 
Table 1. Comparative growth performances of control male and female tilapia under cage culture system.

\begin{tabular}{|l|l|l|l|}
\hline Category & \multicolumn{3}{|c|}{ Growth parameters } \\
\hline & & & \\
\hline & Weight $(\mathrm{g})$ & Length $(\mathrm{cm})$ & Depth $(\mathrm{cm})$ \\
\hline & & & \\
\hline Control male & $77.1 \pm 0.07$ & $18.76 \pm 0.07$ & $6.4 \pm 0.05$ \\
\hline & & & \\
\hline Control female & $65.4 \pm 0.08$ & $13.46 \pm 0.05$ & $6.2 \pm 0.02$ \\
\hline
\end{tabular}

Table 2. Comparative account of different growth parameters for mixed-sex and monosex tilapia under cage culture system. Similar alphabets denote homogenous means.

\begin{tabular}{|c|c|c|c|c|c|}
\hline Category & \multicolumn{5}{|c|}{ Growth parameters } \\
\hline & DWG (g/day) & SGR (\%) & FCR & PER & ANPU (\%) \\
\hline Mixed-sex & $0.39^{\mathrm{b}} \pm 0.003$ & $4.38^{\mathrm{b}} \pm 0.05$ & $3.80^{\mathrm{a}} \pm 0.003$ & $0.85^{\mathrm{b}} \pm 0.01$ & $12.0^{\mathrm{a}} \pm 0.4$ \\
\hline Monosex & $1.17^{\mathrm{a}} \pm 0.006$ & $4.98^{\mathrm{a}} \pm 0.05$ & $3.78^{\mathrm{b}} \pm 0.0006$ & $0.90^{\mathrm{a}} \pm 0.01$ & $7.0^{\mathrm{b}} \pm 0.3$ \\
\hline
\end{tabular}

Table 3. Body composition analysis of control male, control female and androgen treated male under cage culture system. Similar alphabets denote homogenous means.

\begin{tabular}{|l|l|l|l|l|}
\hline Treatment category & \multicolumn{4}{|c|}{ Body composition (\% wet weight basis) } \\
\hline & & & & \\
\hline & Water & Protein & Fat & Ash \\
\hline & & & & \\
\hline Cotrol male & $85.15^{\mathrm{a}} \pm 0.06$ & $11.23^{\mathrm{c}} \pm 0.09$ & $1.4^{\mathrm{c}} \pm 0.07$ & $2.08^{\mathrm{c}} \pm 0.05$ \\
\hline & & & & \\
\hline Control female & $81.48^{\mathrm{b}} \pm 0.2$ & $12.25^{\mathrm{b}} \pm 0.1$ & $2.93^{\mathrm{a}} \pm 0.09$ & $2.68^{\mathrm{b}} \pm 0.09$ \\
\hline & & & & \\
\hline Treated male & $78.78^{\mathrm{c}} \pm 0.1$ & $15.45^{\mathrm{a}} \pm 0.1$ & $1.65^{\mathrm{b}} \pm 0.06$ & $3.73^{\mathrm{a}} \pm 0.09$ \\
\hline
\end{tabular}




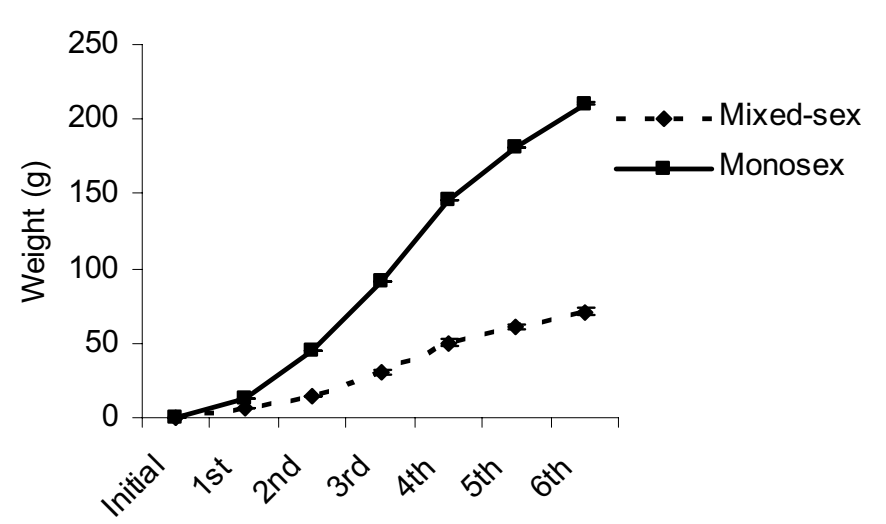

Culture duration (months)

B.

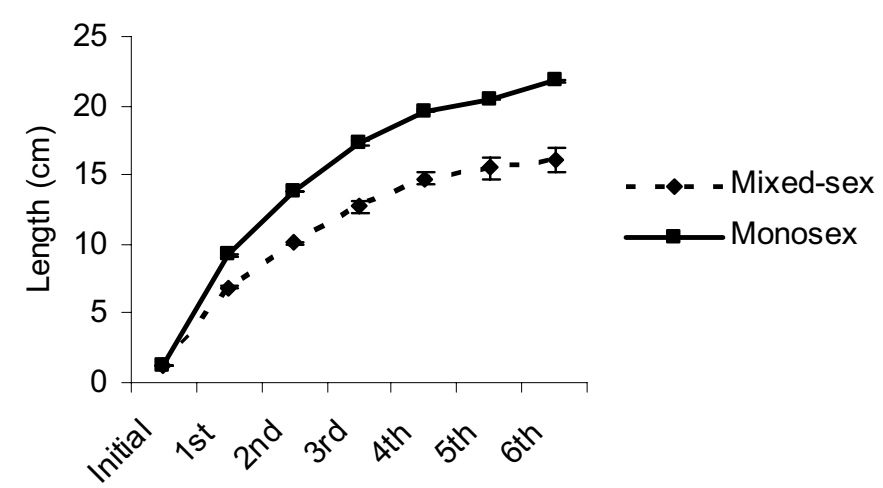

Culture duration (months)

C.

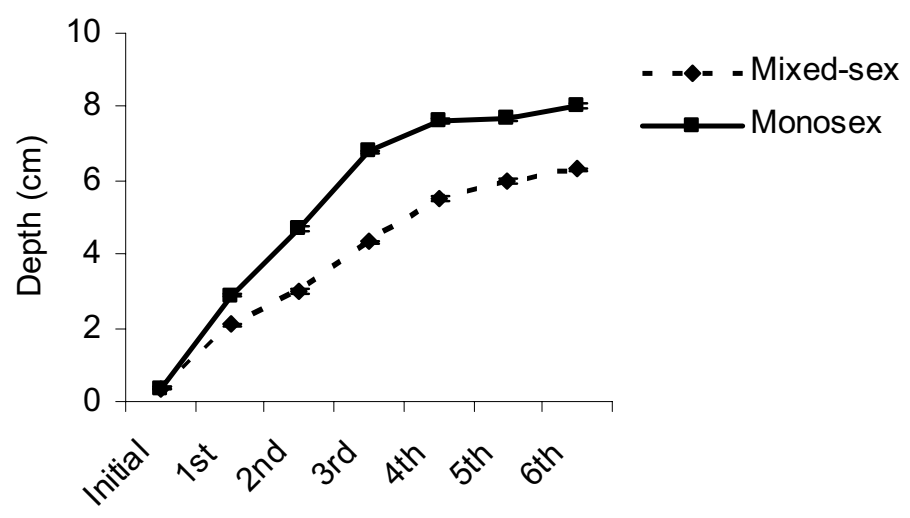

Culture duration (months)

Figure 1. Growth patterns (A: Weight; B: Length; C: Depth) of mixed-sex and monosex fish under cage culture system 